\title{
Cuando las negras se desnudan: la experiencia inasible del cuerpo caribeño y afrodiaspórico en la creación plástica de María Magdalena Campos-Pons y la narrativa de Mayra Santos Febres
}

\author{
When Black Women Strip: The Intangible Experience of Caribbean \\ and Afro-diaspora Body in the Plastic Creations of Maria Magdalena \\ Campos-Pons and the Narrative of Mayra Santos Febres
}

Quando as negras despiam-se: experiência inapreensível do corpo caribenho e afrodiaspórico na criação plástica de María Magdalena Campos-Pons e a narrativa de Mayra Santos Febres

\section{Odette Casamayor-Cisneros}

UNIVERSITY OF CONNECTICUT-STORRS, ESTADOS UNIDOS

Profesora Asociada de Estudios Culturales y Literatura Latinoamericana en la Universidad de Connecticut-Storss. Doctora en Arte y Literatura de la École des Hautes Études en Sciences Sociales, París. Su libro Utopía, distopía e ingravidez: Reconfiguraciones cosmológicas en la narrativa post-soviética cubana fue publicado por IberoamericanaVervuert en 2013. Entre sus más importantes artículos figuran "Guanajerías postsoviéticas: Apuntes ético-estéticos en torno al humor en la narrativa de Ena Lucía Portela" (Premio 2009 de Ensayo "José Juan Arrom" otorgado por la Unión de Escritores y Artistas de Cuba) y "Negros de papel. Algunas apariciones del negro en la narrativa cubana después de 1959" (Premio 2003 "Juan Rulfo" de ensayo literario, otorgado por Radio France Internacionale). Correo electrónico: odette.cisneros@uconn.edu

Artículo de reflexión

Este artículo forma parte de una amplia investigación sobre nuevos procesos de identificación afrodiaspórica en las Américas, y particularmente en Cuba, que desarrollo dentro mi próximo proyecto de libro On being Blacks: Challenging the Hegemonic Knowledge Through Racial Self-identification Processes in Post-Soviet Cuban Cultural Production. Documento accesible en línea desde la siguiente dirección: http://revistas.javeriana.edu.co 


\section{Resumen}

Estudiando nuevas expresiones de la experiencia afrodiaspórica en las Américas, este artículo examina la obra de dos importantes creadoras negras del Caribe: la artista plástica cubana residente en los Estados Unidos, María Magdalena CamposPons (1959), y la escritora puertorriqueña Mayra Santos Febres (1966). Se analizan particularmente las maneras en que sus obras recrean procesos de identificación de género, raza y nación en el Caribe y su diáspora. Cuerpo, performance, erotismo y ritualidad configuran los ejes principales articulando estas investigaciones.

Palabras clave: identidad; afrodiáspora; mujeres; sexualidad; performance

\section{Abstract}

This article explores new expressions of the Afro-diasporic experience in the Americas by examining the work of two prestigious Caribbean Black women: María Magdalena Campos-Pons, Cuban visual and performative artist currently living in the United States, and Puerto Rican writer Mayra Santos Febres. I study particular processes of gender, race and national identification in the Caribbean and its diaspora. Body, performance, erotics, and ritual articulate the main axes of my inquiries.

Keywords: Identity; afrodiaspora; women; sexuality; performance

\section{Resumo}

Estudando novas expressões da experiência afrodiaspórica nas Américas, este artigo examina a obra de duas importantes criadoras negras do Caribe: a artista plástica cubana residente nos Estados Unidos, María Magdalena Campos-Pons (1959) e a escritora porto-riquenha Mayra Santos Febres (1966). Analisam-se, particularmente, as maneiras em que suas obras recriam processos de identificação de gênero, raça e nação no Caribe e sua diáspora. Corpo, performance, erotismo e ritualidade configuram os eixos principais articulando tais pesquisas.

Palavras-chave: identidade; afrodiáspora; mulheres; sexualidade; performance

\section{Cómo citar este artículo:}

Casamayor-Cisneros, Odette. "Cuando las negras se desnudan: la experiencia inasible del cuerpo caribeño y afrodiaspórico en la creación plástica de María Magdalena Campos-Pons y la narrativa de Mayra Santos Febres". Cuadernos de Literatura 19.38 (2015): 137-158. http://dx.doi.org/10.11144/Javeriana.cl19-38.clnd 
"I know how powerful a body is, just in being there"

"No PODEMOS LUCHAR contra los viejos poderes utilizando solamente los mismos términos creados por esos viejos poderes. La única manera en que podemos hacerlo es creando otra estructura que incluya cada aspecto de nuestra existencia, a un tiempo que vamos resistiendo" , respondía Audre Lorde a Adrienne Rich en $1979^{2}$. Es ahora mi intención, con las investigaciones que presento en este ensayo, explorar esas estructuras diferentes a través de las cuales se desarrollan inusitados, "cimarrones"3 terrenos de rebeldía contrahegemónica. Para ello propongo el escrutinio del cuerpo y la experiencia femenina y afrodiaspórica en las Américas, analizando precisamente el trabajo de dos importantes creadoras negras del Caribe: la artista plástica cubana residente en los Estados Unidos, María Magdalena Campos-Pons (1959) y la escritora puertorriqueña Mayra Santos Febres (1966). Estudio las maneras en que en algunas instalaciones fotográficas y performances de Campos-Pons y en la novela Fe en disfraz de Santos Febres, se recrean procesos de identificación de género, raza y nación en el Caribe y su diáspora.

Focalizo mi análisis en los inasibles movimientos del cuerpo y la experiencia de las mujeres negras con el anhelo de acercarme a lo indecible. Es decir, aquellos espacios de la expresión que escapan al discurso y por ello no pueden incluirse dentro de los modos expresivos creados y en consecuencia epistemológicamente regidos por poderes hegemónicos.

En esta búsqueda atiendo también a la ambivalencia que Stuart Hall reconocía en las estructuras de idenficación ${ }^{4}$. En los cuerpos femeninos, negros,

1 Salvo anotación particular, todas las traducciones son mías.

2 "[W]e cannot fight old power using old power terms only. The only way we can do it is by creating another whole structure that touches every aspect of our existence, at the same time as we are resisting" (Lorde, "An Interview...." 102).

3 Cimarrón es el término bajo el que se designa al esclavo fugitivo en las Américas de habla hispana. En el contexto de este artículo, no lo utilizo en primera instancia para expresar un acto de fuga, sino para aludir la contestación marginal, utilizando medios y caminos poco transitados para enfrentar poderes hegemónicos.

4 "The structure of identification is always constructed through ambivalence. Always constructed through splitting. Splitting between that which one is, and that which is the other. [...] The unspoken silence in between that which can be spoken is the only way to reach for the whole history. There is no other history except to take the absences and the silences along with what can be spoken" [...] (Hall, "Old and new ..." 201-203). 
caribeños, que descubrimos en las creaciones de Magdalena Campos-Pons y Mayra Santos Febres, "resuena" ese "indecible silencio" presentado por Hall como un terreno de necesaria exploración. Son esos silencios perceptibles a través de la expresión performativa a la que se entregan los personajes de la escritora y artista caribeñas, los que determinan el recorrido propuesto en este artículo.

\section{En los entreactos de la tragedia identitaria}

María Magdalena Campos-Pons concibió a finales de los años 1990 una de sus series fotográficas más interesantes, "When I am not here, estoy allá". Con este título, que ya es en sí mismo una suerte de performance retórico, abre de inmediato la artista interrogantes omnipresentes en la totalidad de su obra: $\mathrm{i}$ Dónde exactamente se posiciona el sujeto? ¿Here o allá? Y, lo más importante, ¿cuál serían aquí y allá? A través del juego con las palabras en inglés y en español, el título de la serie describe difusos desplazamientos, entre Cuba y los Estados Unidos pero también entre África y las Américas, que apuntan hacia la ambigüedad identitaria del sujeto. Las piezas de esta serie están constituidas por fotografías de la artista expresando múltiples cuestionamientos en torno a la identidad cultural, histórica, racial, idiomática, nacional, ideológica y de género.

Estudio particularmente las obras que conforman la serie "When I am not here, estoy allá" para introducir una temática esencial en mis investigaciones: los "enigmáticos" procesos de identificación. La conceptualización que posibilita el adentrarse en esta problemática proviene aquí, en primera instancia, de las teorías desarrolladas por Stuart Hall. Me refiero entonces a procesos de identificación y en modo alguno al tradicional concepto de identidad. Son procesos de invención y deshacimiento coincidentes que Hall metaforiza como articulación y sutura en su búsqueda por teorizar la identidad,

$[\ldots]$ no como aquello que fija el juego de la diferencia en un punto de origen y estabilidad, sino como lo que se construye en y a través de la différance [derrideana] y es constantemente desestabilizado por lo que excluye ("¿Quién necesita..." 19) (destacado de la autora).

Bajo la perspectiva de Hall, es posible comprender cómo se arma y desarma la identidad, a través de la historia y en el presente, en la vida social del sujeto. La exigencia de adoptar nuevas perspectivas desde las cuales pensar estos fenómenos desemboca así en la crítica de la comprensión identitaria, que constituye un elemento esencial en este artículo. Se trata entonces de aprehender la identidad como la sutura a la que se refiere Hall: 
[...] un punto de encuentro [yo sugiero, desencuentro] entre, por un lado, los discursos y prácticas que intentan "interpelarnos", hablarnos o ponernos en nuestro lugar como sujetos sociales de discursos particulares y por otro, los procesos que producen subjetividades, que nos construyen como sujetos susceptibles de "decirse". (20)
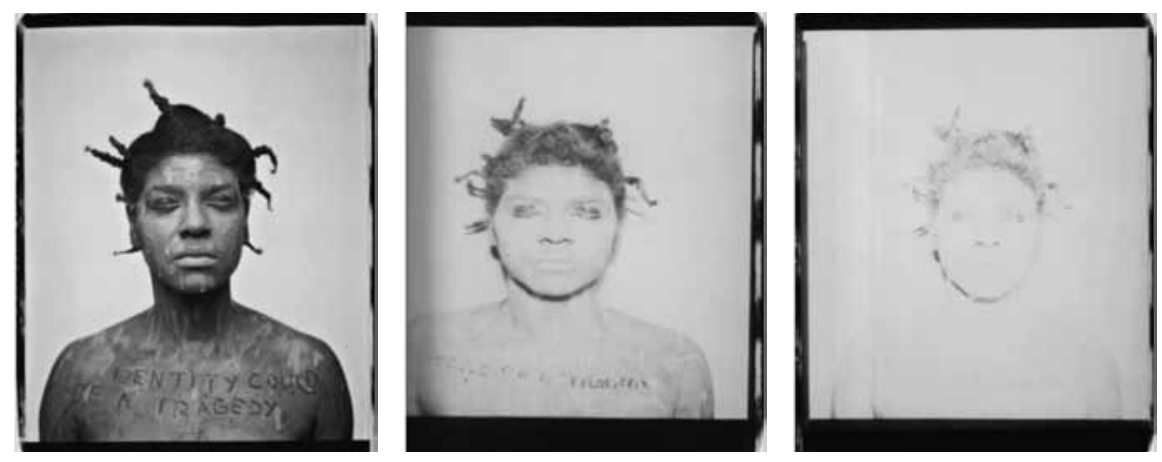

Fig. 1. María Magdalena Campos-Pons, "Identity could be a Tragedy", 1996. (Fragmentos)

Al presentar el concepto de identificación Stuart Hall parte del reconocimiento de que en la idea de la identidad hay siempre "demasiada" o "demasiado poca" definición (15), lo cual acarrea su propuesta interpretativa de la identificación como sutura. Estas sobre-determinación y carencia explicativas, inherentes a la identidad a las que Hall alude en sus formulaciones tienen también notoria presencia en la obra de María Magdalena Campos-Pons. Precisamente una pieza dentro de la serie "When I am not here, estoy alla"" recrea estos fenómenos: "Identity could be a tragedy" es su título, expresando con ello la dificultad de la definición identitaria. Esta pieza consta de seis polaroides mostrando el torso desnudo de la artista. Sobre su piel negra se lee la frase "Identity could be a tragedy", que va sin embargo desapareciendo gradualmente, junto con la fotografía de Campos-Pons. La última polaroide apenas muestra el rastro de su figura tras una gran mancha blanca, enceguecedora como si fuese luz. Ya en esta imagen se ha borrado totalmente la frase, expresión de la tragedia derivada por la paradoja intrínseca de la identidad como concepto: su simultánea necesidad e imposibilidad.

El texto en que Hall desarrolla estas teorías se titula "¿Quién necesita la identidad?" ("Who needs Identity?"), y en él subraya la necesidad para el sujeto contemporáneo de pensar la identidad como un concepto "que funciona 'bajo borradura' en el intervalo entre inversión y surgimiento" (14). El pronombre 
quien, para Stuart Hall, es un sujeto en plena y constante creación y destrucción. Aparece y se desvanece al unísono y en todo momento, como sugieren las polaroides en "Identity could be a Tragedy", donde ya hemos visto que la imagen y la frase desaparecen según se llega a la última foto de la serie. Coinciden estas representaciones y las teorías de Hall con las interpretaciones de la identidad desarrolladas por Jean-Luc Nancy, para quien el quien (qui) también aparece en primer plano. En L'Identité (2010) todo un capítulo es dedicado a responder a esta pregunta Qui? Refiriéndose en principio a una presunta identidad francesa, Nancy dirige una doble pregunta ¿Quiénes son los franceses? y ¿Quién propone la pregunta sobre la identidad nacional? (43-44). Continúa su disquisición conviniendo en que "si cada francés -como todo ser humano- es un quien, y si ese quien no podrá nunca reducirse a un qué, Francia en sí es otra especie de quien irreductible a ninguna característica específica" (destacado de la autora) ${ }^{5}$. Como Stuart Hall, Jean-Luc Nancy confirma que la identidad es a la vez un punto y un laberinto, que su secreto estriba en el vaivén del uno al otro, en el permanente contacto y desprendimiento: "Uno está entonces destinado a perderse en el Uno o a perderse en el Otro" ". Estas ideas pueden asimismo relacionarse con la historia que Mayra Santos Febres ofrece en la novela Fe en Disfraz (2009), que en efecto sugiere varias reflexiones sobre identidad y alteridad.

Se narran en este libro las experiencias del historiador Martín Tirado, quien se enamora de su jefa Fe Verdejo, directora de un seminario de investigaciones en la Universidad de Chicago. Fe es negra, de origen venezolano. Tirado, blanco puertorriqueño, es arrastrado por una pasión inusitada a ejecutar rituales sadomasoquistas que Fe organiza desde que descubriera, en el convento de Recogimiento de las Macaúbas en Brasil, un lujoso traje atribuido a la legendaria esclava dieciochesca Xica da Silva. La Dra. Verdejo investigaba testimonios dejados por antiguas esclavas relatando el maltrato físico y moral al que eran sometidas. Al descubrir que el traje cubría un arnés cuyos alambres torturaban la carne, decide vestirlo cada 31 de octubre, Noche de Brujas, sufriendo en su propio cuerpo las laceraciones metálicas. Cuando incorpora a su subalterno blanco Martín Tirado al rito, la jefa negra Fe Verdejo introduce nuevos factores raciales, socioculturales, sexuales, genéricos.

"Or si chaque Français est un qui, à l'instar de tout autre sujet humain, et si ce qui ne sera jamais réductible à un quoi, la France elle-même est un autre espèce de qui irréductible à aucune caractéristique" (Nancy, L'Identité 44, destacado de la autora).

6 "Un point et un labyrinth, voilà le secret d'une identité. De l'un à l'autre, contact permanent et dehiscence permanente. On est donc voué soit à perdre l'un soit à se perdre dans l'autre" (Nancy, L'Identité 43). 
Complicadas relaciones de poder, afiebradas por el eros, duelen y provocan placer en los cuerpos de los protagonistas. Las potentes sensaciones viajan además a través de la Historia. Para Fe, se trata de revivir la experiencia de las esclavas cuyos testimonios estudia. La pregunta implícita sería: ¿Estos testimonios, la palabra, la historia, bastan para aprehender lo ocurrido, en este caso, la existencia de las mujeres negras durante la vida colonial y en el presente? Fe Verdejo necesita además sentir en su cuerpo experiencias que no conoció porque vive en el siglo XXI, pero con las que se siente esencialmente identificada. ¿Por qué se produce esta identificación? ¿Por ser mujer? ¿ ¿Por ser negra? El sufrimiento que siente al proceder con sus investigaciones es innegable. Pero cpor qué ocurre así? Es en el transcurrir de estas preguntas que puede accederse a la consideración del sujeto no a través de identidades fijadas a su experiencia, sino en el proceso simultáneo de construcción y borradura de esas identidades. En los intersticios dejados por estos procesos anida aquel indecible silencio, indispensable a todo intento por recuperar una historia integral, referido por Stuart Hall al defender una contradictoria noción de identidad "compuesta por más de un discurso, en los silencios del otro, escrito dentro y a través de la ambivalencia y el deseo" $"$.

Para aprehender tales intersticios, conviene en mi opinión recurrir a la comprensión identitaria a partir de la noción de performance, como ha propuesto consistentemente Judith Butler. Sus teorías en torno a la construcción de las identidades genérica y sexual como series de repeticiones desarrolladas mediante sucesivos actos performáticos, pueden extenderse a todo proceso de identificación humana. La perspectiva de Butler, quien también parte del reconocimiento de la incoherencia intrínseca del ser, de la inexistencia de una clara identidad, perfectamente determinada y esencial, conduce a la concepción del género como un performance que produce la ilusión de poseer un sexo propio, una esencialidad genérica (134). Pero se trata solo de una ilusión producida por la repetición performática. "La sexualidad nunca es totalmente expresada en un performance o práctica" (Butler 131, destacado de la autora) ${ }^{8}$, expresaba Butler en una frase que, excediendo la identificación sexual y genérica, puede muy bien leerse en palimpsesto con ciertos postulados de Stuart Hall. Asimismo Butler reconoce que esta repetición de performance constitutivos de la identidad requiere

"The notion of identity as contradictory, as composed of more than one discourse, as composed always across the silences of the other, as written in and through ambivalence and desire. These are extremely important ways of trying to think an identity which is not a sealed or closed totality" (Hall, "Old and new..." 201-203).

8 "Sexuality is never fully expressed in a performance or practice" (Butler 131, destacado de la autora) 
la existencia de intervalos entre los actos. Desde tales "entreactos", el riesgo y el exceso amenazan siempre con interrumpir el continuum de la identidad que está siendo, al mismo tiempo, constituida ${ }^{9}$. No es difícil corresponder tales intervalos o entreactos con los silencios indecibles mencionados por Hall.

Manteniendo coherencia con el propósito inicialmente esbozado de explorar, como incitaba Lorde, epistemologías no reconocidas tradicionalmente por los poderes hegemónicos, que abarquen cada aspecto de la existencia a un tiempo que ofrezcan espacios de resistencia, vale entonces enfatizar la observación de los performance identitarios. El performance es primordialmente efectuado por el cuerpo. Y al cuerpo en consecuencia dedico las próximas líneas de este escrutinio de la obra de María Magdalena Campos-Pons y Mayra Santos Febres.

\section{Penetración, herida y éxtasis identitario: cuerpos en performance erótico}

En el cuerpo, que parece ser el sitio privilegiado para expresar identidades inasibles pero inevitables, se revela la interrogación identitaria desarrollada en la novela Fe en disfraz. Asimismo, es en el cuerpo donde la artista María Magdalena Campos Pons inscribe preferentemente sus exploraciones en torno a las identidades. Y es que el cuerpo constituye, como recuerda Jean Luc Nancy cuando lee a Freud, ausgedehnt, extensión de la efracción que es la existencia, extensión del ahí, del lugar de efracción a través del cual el ser puede aparecer en el mundo (Corpus 24). Mas la preponderancia del cuerpo en estas obras, ya precisamente dentro del marco de la experiencia afrodiaspórica en las Américas, nos acerca a los análisis de Patricia Hill Collins, Saidiya Hartman, Jenny Sharpe, Vera M. Kutzinski y bell hooks, entre otras investigadoras. La misma Santos Febres, como reconoce Chrissy B. Arce en su estudio de Fe en disfraz, ha discutido en ensayos previamente publicados la complejidad de la sexualidad de la mujer esclava y la difícil aplicación de concepciones eurocentristas del erotismo ${ }^{10}$.

Se comprenden entonces los mecanismos en torno a los cuales la raza y la sexualidad han constituido discursos superpuestos cuyos orígenes, según ha explicado hooks refiriéndose a los Estados Unidos, aunque puede extenderse a la totalidad de la afrodiáspora en las Américas, remontan a la esclavitud. Desde su punto de vista, el cuerpo de las mujeres negras constituyó desde entonces el terreno discursivo, los campos de juego donde racismo y sexualidad convergie-

"If every performance repeats itself to institute the effect of identity, then every repetition requires an interval between the acts, as it were, in which risk and excess threaten to disrupt the identity being constituted" (Butler 134).

10 Ver Arce (2011) y Santos Febres. 
ron (hooks 57). Ha destacado hooks la necesidad de desarrollar más estudios "sicosexuales de la esclavitud" que exploren las condiciones en las cuales la sexualidad sirvió como fuerza capaz de subvertir y romper con las relaciones de poder, irrumpiendo contra el paradigma opresor/oprimido; "la violación constituye una metáfora apropiada de la colonización imperialista europea" $(57-58)^{11}$. El énfasis que la socióloga coloca en la perspectiva sicosexual de estas necesarias investigaciones sostiene la relación que introduzco entre sus reflexiones y mi estudio de Campos-Pons y Santos Febres. Desde las artes visuales y el performance artístico, en el caso de la primera, y la narrativa en cuanto a la segunda, pueden leerse vibrantes y ficcionales respuestas a los presupuestos esbozados por hooks.

Los cuerpos de las mujeres negras en la prosa de Santos Febres tanto como en las fotografías y performances de Campos-Pons, sugieren intensas migraciones del cuerpo y del sujeto. Son mujeres en quienes se inscribe, primeramente, la experiencia afrodiaspórica, por ser descendientes de africanos traídos a través de la Trata Negrera para trabajar como esclavos en las Américas. En este sentido, las historias carnales encerradas en los cuerpos representados, "hablan" del desplazamiento forzado de un continente a otro, de determinadas culturas y sociedades hacia otras. Eran además cuerpos despojados de humanidad, pues se les consideraba bajo la esclavitud solo instrumentos de trabajo, bestias, "piezas de ébano". El carácter forzado de todas estas experiencias acarrea la violencia y la rabia remanentes, la violación que subyace en recuerdo eslabonado de una generación a otra.

La protagonista de Fe en Disfraz se forma dentro de este tipo de círculos de violencia anecdótica (la historia de las esclavas maltratadas que estudia, la de Xica da Silva, presunta propietaria original del traje torturante, las de sus descendientes que conservaron oculto el traje, y finalmente las historias de la propia $\mathrm{Fe}$ Verdejo, su madre y su abuela, quienes todas fueron violadas -o al menos desvirgadas- y abandonadas por hombres blancos). Como constancia de su condición, signada por las violencias de la historia, su cuerpo negro permanece. El cuerpo no es un traje que Fe Verdejo pueda cambiar según las circunstancias. Tanto las primeras dueñas del famoso traje como la abuela y la madre de Fe intentaron en su tiempo 'disfrazarse' de mujeres diferentes a las negras poseídas y forzadas por hombres blancos que en realidad fueron. Fe Verdejo fue internada en un colegio

11 "Race and sex have always been overlapping discourses in the United States. That discourse began in slavery ... black women's bodies were the discursive terrain, the playing fields where racism and sexuality converged. Rape as both right and rite of the white male dominating group was a cultural norm. Rape was also an apt metaphor for European imperialist colonization of Africa and North America" (hooks 57-58). 
de monjas por su abuela, quien ya había hecho lo mismo con la madre de Fe. La voluntad inicial de la protagonista había sido acercarse al modelo que le ofrecían las monjas: "Yo quería ser como aquellas monjas, blancas, puras, como aquellas princesas; vestir trajes hasta el suelo, hechos de terciopelo con hilos de oro y pedrerías" (89). Mas quedaba siempre su piel "mapa de mis ancestros", para recordarle su real, imborrable condición. Tal situación demuestra, señala Arce, como tanto el disfraz de Fe como la ropa de Xica anuncian la imposibilidad de una integración armónica del subalterno dentro de la cultura dominante (235). Debajo de los ricos trajes, la piel negra le devuelve a la protagonista la historia de los cuerpos de sus antepasados, desnudos y lacerados por la esclavitud y la violación: "ninguna tela que la cubriera, ni sacra ni profana, podría ocultar mi verdadera naturaleza" (Santos 89). Y esto, ni siquiera cuando años después disimula su pasado histórico y personal, el telúrico erotismo que la domina, tras la hierática e impoluta imagen de la académica severa.

Me interesa expandir esta comprensión del uso del traje como expresión de una imposible identificación total con los valores dominantes, más allá del pivotal traje de Xica. Me detengo en el actual disfraz de Fe Verdejo, que describe Martín Tirado extasiado frente a la mesa de trabajo:

[...] su piel tersa, oscura [...] Llevaba el pelo siempre recogido en un moño apretado contra la nuca. [...] [F]alda de paño oscuro y una discreta camisa blanca. Blanco y negro ella toda, pupilas contra su cara, sus dientes contra sus labios, camisa contra piel. Blanco y negro era su hábito, como el de una monja. Ese fue el primer disfraz que le conocí. Disfraz de historiadora. (Santos 34)

Considero que los disfraces sobre el cuerpo de las antepasadas de Fe y sobre la historiadora misma no constituyen solamente cárceles o inapropiadas vestiduras camuflando su intimidad. Son también armas usadas por unos y otros personajes para traspasar epistemologías hegemónicas. Penetrando en la carne, son trazados nuevos túneles hacia un saber más completo de la experiencia de las mujeres negras en las Américas. Propongo valorar el uso de estos disfraces en la novela de Santos Febres como actos performativos en los que se puede leer la historia indecible, aunque insoslayable.

Pues también de su imagen pública Verdejo se deshace; pero actúa en secreto, silenciosamente. Siempre con rigor de profesional, la exitosa historiadora recupera la memoria de tantas violaciones usando, además del propio, el cuerpo -y la pasión- de su subalterno profesional, el blanco Martín Tirado. Las tradicionales relaciones de poder son aquí subvertidas a través del ambiguo deseo experimentado por Fe Verdejo. "Las mujeres negras eran objetos para ser 
vistos, disfrutados, comprados y usados primeramente por hombres blancos y con dinero" (Collins 31), recordemos con Patricia Hill Collins ${ }^{12}$. Pero en $\mathrm{Fe}$ en disfraz el cuerpo -muy negro según la descripción que en la novela se hace del personaje- usualmente utilizado para reafirmar la dominación del hombre blanco, es ahora el que dicta la acción. Desde el llamado del placer, Fe exige y ordena. Es fuerza inapelable y así lo reconoce Tirado quien, dominado por su deseo de $\mathrm{Fe}$, se reconoce

[..] más pálido que nunca. De mi piel ha desaparecido todo indicio de color [...] me encuentro de una blancura vulnerable, como de animal a punto de ser degollado. No me queda más que esa blancura que es mi herida. Fe me lo ha hecho ver, la herida que habita mi piel. (20)

La amante negra es por supuesto el otro contra el cual Martín Tirado confirma su identificación como sujeto blanco y masculino. Fe Verdejo representa aquel otro retratado por Emmanuel Lévinas en su conceptualización de lo que denominaba La epifanía del otro. La historiadora encarna entonces la presencia, una "visitación" que según el filósofo francés consiste en "venir hacia nosotros", en hacer una "entrada" (Lévinas 50), o una herida en la carne del blanco Tirado. "La presencia del rostro señala también un orden irrecusable -un mandamientoque interrumpe la disponibilidad de la conciencia" (Lévinas 51$)^{13}$, e interrumpe los discursos preconcebidos, es decir los estereotipos, las normas sociales, la tradición. Por eso el protagonista se desconcierta y no sabe cómo responder a la llamada que en su cuerpo provoca la visitación de Fe Verdejo, al ser penetrada penetrando su identidad de hombre blanco.

En la novela de Santos Febres los procesos de identificación racial y genérica del hombre blanco se verifican a través de la herida que el protagonista descubre en sí, provocada por su exposición a ese otro que es Fe Verdejo. La mujer negra hace que la blancura le duela a Martín Tirado. Tras sus primeras ceremonias masoquistas de la Noche de Brujas, cuando la protagonista, ofreciendo placer al hombre se encaja con cada movimiento más profundamente los alambres del arnés en su piel, Tirado se siente avergonzado, prefiere huir: "Había sido yo el penetrado, el desnudo. Yo, el venido. Los ojos de Fe, su silencio [...]

12 "Black women were objects to be seen, enjoyed, purchased, and used, primarily by White men with money" (Collins 31).

13 "La présence du visage signifie ainsi un ordre irrecusable -un commandement- qui arrete la disponibilité de la conscience. La conscience est mise en question par le visage. La mise en question ne revient pas à une prise de conscience de cette mise en question. L" "absolument autre" ne se reflète pas dans la conscience" (Lévinas, 51). 
me lo hicieron saber [...] aquel silencio me obligó a escapar" (Santos 59). Y es que la epifanía del otro constituye según Lévinas una irrupción no discursiva. Fe, lo absolutamente otro, es una interrupción sin palabras e inesperada en el orden pre-establecido.

Mientras el hombre blanco teme a su propio placer junto a la mujer negra, que le revela experiencias inéditas, esta también parece encontrar cierto placer en el dolor auto-infligido. En lo aparentemente inexplicable de ese placer, ante el cual Martín desvaría subyugado, late la experiencia identitaria de la protagonista negra. No se agitan en el performance que envuelve a Tirado y Verdejo solo los deseos de penetrar al otro, generalmente identificados con tradicionales prácticas dominantes, sino también la propia búsqueda íntima de la protagonista negra que sabe que tiene que encontrar nuevos caminos para comprenderse a sí misma y su historia. El erotismo recreado por Santos Febres ilustra la pertinente defensa del conocimiento erótico emprendida por Audre Lorde en múltiples ensayos, pues es a través de este que los protagonistas de Fe en disfraz acceden a los más recónditos espacios de su existencia ${ }^{14}$.

Tales procesos se consiguen dentro de un complejo entramado de sensaciones experimentadas por los cuerpos, penetrándose mutuamente en el encuentro de la mujer negra y el hombre blanco. Es el momento de la experiencia y la sensación, desnudo de palabras al punto de aterrar al sujeto supuestamente hegemónico. Y todo se desencadena a partir del sufrimiento carnal de la protagonista, tradicionalmente sujeto subalterno, a causa de las heridas perpetradas por el arnés del traje que ella, como sus antecesoras negras, insiste en vestir. Por el placer que extrae del dolor Fe Verdejo, se reafirma además como sujeto total. Condición esta negada a las esclavas y más recientemente, ya abolida la esclavitud, en las sociedades del occidente contemporáneo, condición difícilmente asociada a las mujeres negras, por lo general discriminadas. El alcance de estos procesos puede leerse en algunas reflexiones de Fe Verdejo:

[L]a historia está llena de mujeres anónimas que lograron sobrevivir al deseo del amo desplegándose ante su mirada. Pero nunca se abrieron completas $[\ldots]_{\mathrm{C}}$ Cómo hicieron para que la piel se ofreciera sin traicionar lo que tenía que permanecer escondido? ¿Cómo hacer ahora para que esa piel cuente la

14 Pueden recordarse las consideraciones de Lorde en su célebre ensayo "Uses of the Erotic": "Our erotic knowledge empowers us, becomes a lens through which we scrutinize all aspects of our existence, forcing us to evaluate those aspects honestly in terms of their relative meaning within our lives. And this is a grave responsibility, projected from within each of us, not to settle for the convenient, the shoddy, the conventionally expected, not the merely safe." (Lorde, "Uses..." 57). 
verdadera historia de estos seres que accedieron a la esfera limitadísima de su libertad, a cambio de un asco disfrazado de ardor, de una violencia hecha devoración sagrada? (46)

Fe Verdejo busca la Historia, de la cual es especialista, en la piel. Se enfrasca en redoblar -o contrarrestar- los saberes académicos con otros, los de la experiencia y lo sensorial. En los performances interpretados por los amantes se descubren aquellos intersticios por los que se filtra la ambivalencia de sus identidades respectivas, los "entreactos" podría decirse si volvemos a las formulaciones de Butler. La carne de la mujer negra deviene terreno para varias transacciones: es el cuerpo del otro tomado por el hombre blanco a un tiempo que abre en este heridas, interrogaciones sobre su identidad hegemónica. Pero es también el territorio donde la mujer negra inquiere sobre sí misma, se auto-penetra y reinventa. Alcanzar el orgasmo es acceder a una paz absoluta donde su yo más real, el cuerpo de Fe Verdejo, alcanza una comunión transhistórica con los cuerpos sufrientes de sus antepasadas. Su cuerpo no es entonces solo espacio dominado o espacio de resistencia. Es también donde su dolor más íntimo, corporal, le permite descubrirse a sí misma. No en la posición confrontacional de quien se defiende de la opresión hegemónica, sino en tanto que sujeto aprendiendo a ser a través del conocimiento más profundo de sus propias heridas.

\section{"When I am not here, estoy allá": la experiencia diaspórica}

Otros desplazamientos también son expresados en la carne de la protagonista de Santos Febres y en las obras de Campos-Pons. Hay en ambos casos la huella de la experiencia diaspórica actual, pues Fe Verdejo es venezolana y vive en Chicago; mientras la artista cubana reside y trabaja en Boston. El desplazamiento cultural también deja huellas en estos cuerpos, en trasiego de un espacio cultural a otro. La memoria de sus ancestros y de la infancia pervive sin embargo en ellos.

Así, se descubre en el trabajo de Campos-Pons el sedimento cotidiano de la nostalgia y el recuerdo. Parece a veces esconderse en el agua de los mares, interpuestos entre la artista, su historia y sus ancestros. No es casual que en 2007 el Museo de Arte de Indianápolis compilase su trabajo de veinte años bajo el título "Everything is Separated by Water". Todo ha sido separado por el agua: es el rudo océano golpeando su existencia de sujeto afrodiaspórico. Aunque vale

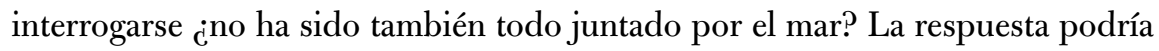
encontrarse tal vez, retrospectivamente, en el título de una instalación de 1994, "The Seven Powers come by the Sea", que expresa la travesía marítima, no solo de los esclavos en las horribles condiciones de la Trata Negrera, sino también de 
los dioses que en las Américas les consolarían en su no-existencia como seres cautivos, acompañando espiritualmente, luego, la vida de sus discriminados descendientes. El título de esta obra hace clara referencia a las Siete Potencias africanas, que en la Santería o Regla de Osha (religión cubana de origen yoruba) son identificados con los orishas (divinidades) principales o a los poderes que estos encarnan. Ha reconocido al respecto la artista que "del océano vino la esclavitud y la tragedia, pero también los siete poderes que llegaron con ellos" (Harris 51$)^{15}$.

El desplazamiento diaspórico no es entonces solo el de los cuerpos y las culturas, es también el de los ancestros y su espiritualidad, mantenida en el presente a través de las religiones cubanas de origen africano. Esta recreación de la espiritualidad y la religión afrodiaspóricas explica por qué Flora González Mandri, en su importante estudio sobre la obra de Campos-Pons, la considera una "artista-santera" (156). Se caracteriza la invocación religiosa en sus creaciones, sin embargo, más por la transmisión de un bagaje espiritual que por la simple reproducción de elementos litúrgicos. Si bien es cierto que Campos-Pons recurre a ciertos atributos de los orishas como collares, el predominio de determinados colores, algún vestuario, rezos; estos elementos aparecen por lo general tan imbricados al cuerpo de la artista que aparentan formar parte del mismo. Con ello metaforizan la más íntima función de las cosmologías de origen africano en la existencia del sujeto afrodiaspórico contemporáneo: más allá de constituir la base de importantes sistemas religiosos, participan de la configuración ontológica del individuo en su existencia presente en las Américas.

En "The Seven Powers come by the Sea", Campos-Pons figura en el centro de esta instalación, marcada su piel negra de números blancos. Los números, hacia los que la artista confiesa experimentar cierta obsesión (Freiman 42), trazan además la continuidad entre el pasado, manifiesto por las planchas representando los esclavos africanos hacinados en el barco negrero, y el presente afrodiaspórico que encarna la artista.

15 "[F]rom the sea came slavery and tragedy, but seven powers came with them" (Harris 51). 


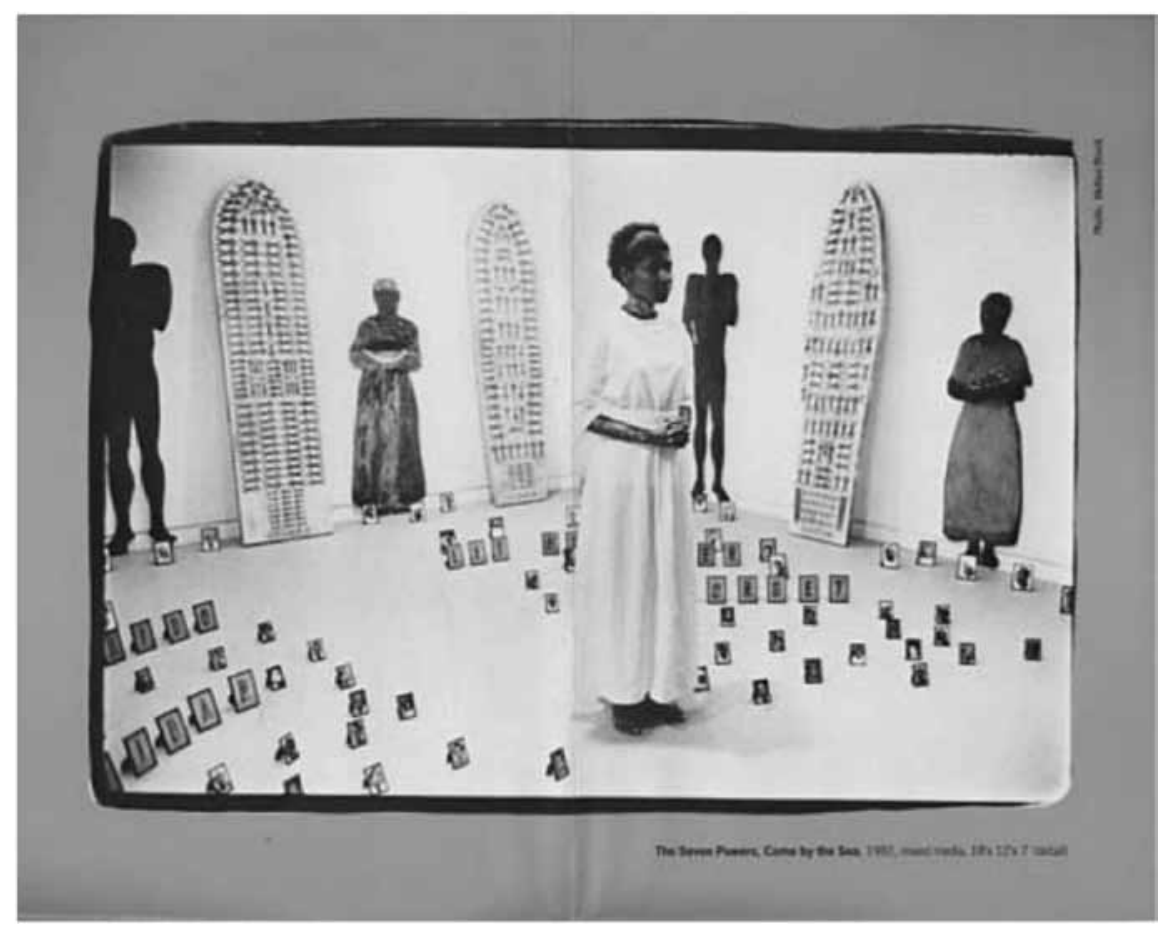

Fig. 2. María Magdalena Campos-Pons, "The Seven Powers come by the Sea", 1994.

Se cuentan en sus obras, entonces, historias de fusión y separación. Travesías torcidas, inestables, enmarañadas, superponiéndose en capas sucesivas que además se confunden entre sí. No hay rectitud ni fijeza aparentes en la concepción creativa de Campos-Pons. Son sinuosos sus cabellos suspendidos en "Elevata" (2002), mientras se hacen enredado vínculo entre los fragmentos del cuerpo interrumpido en "Nesting IV" (2000) o trenzan, en "Nesting III" (2000), nido absoluto con la naturaleza. La fragmentación es notoria en estas polaroides que al mostrar el cuerpo de la artista interrumpido, pueden recordarnos cuán incompletas resultan ser también toda historia e identidad. La evidente búsqueda desmitificadora de los caminos de la identificación racial y nacional en las obras de Campos-Pons trae de vuelta a este análisis la sutura que para Stuart Hall, como ya se ha referido anteriormente, define el proceso de identificación ("¿Quién necesita..." 20). 


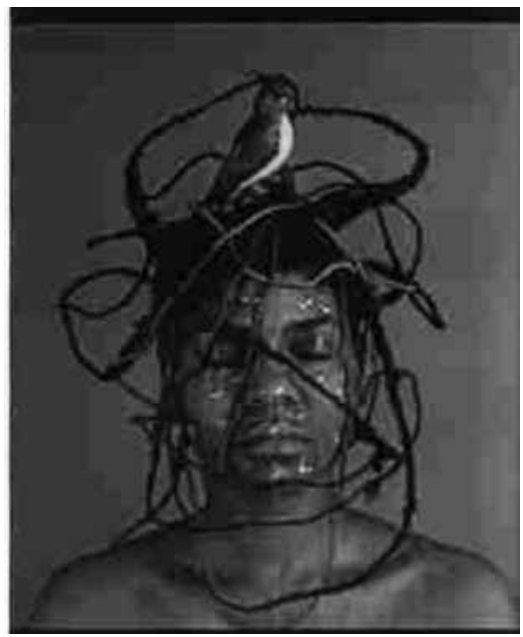

FIg.3. María Magdalena Campos-Pons, "Nesting III", 2000.

En "Elevata", precisamente aparece el torso de espaldas de la artista. A diferencia de "Identity could be a tragedy", en esta obra el cuerpo no se deja llevar en una propuesta discursiva. Sugiere, no dice. Nada es explícito, mucho menos fijo. Su cuerpo ni siquiera ofrece una mirada pues da la espalda al espectador. Invertido, desde el extremo superior izquierdo de la composición, expone una paradoja: ¿Se eleva, como sugiere el título de la obra, o zambulle este cuerpo de inusitada expresividad, a pesar del rostro oculto? Podría tal vez pensarse en cierta suspensión en múltiples intentos de definición identitaria. Gorgona en azul, las trenzas salen de su cabeza -o entran en ella- como ideas enredándose dentro de un mar, creando círculos, englobando ¿iun sol? también azul.

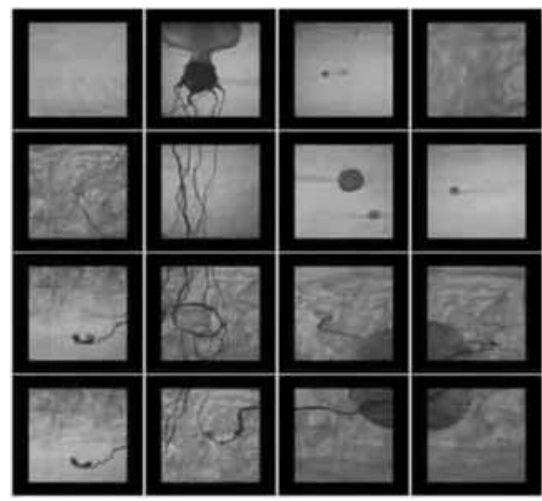

Fig. 4. María Magdalena Campos-Pons, "Elevata", 2002. 
Tanto en las series "Elevata" y "Nesting", como en otras creaciones de Campos-Pons, hilos, collares alusivos a la santería, una trenza de su pelo, pueden sugerir el fragilísimo vínculo, movimiento entre las partes de un cuerpo intraducible, o de este cuerpo con los de su historia y su presente -los parientes que permanecieron en Cuba, los ancestros africanos, su actual familia en los Estados Unidos. En general, en sus trabajos prevalece el movimiento a través de la historia, las genealogías, culturas y territorios. Así, como hilo conductor de historias particulares, de vientre en vientre generador de vida, se extiende en "Umbilical Cord" (1991) el cordón rojinegro, referencia a Elegguá, orisha que inaugura, tuerce y enmienda caminos, impredecible, mas garantizando la continuidad incluso invisible. Sobre esta obra, ha expresado Campos-Pons:

En la pieza ["Cordón umbilical"] aparece cada miembro femenino de mi familia, desde mi abuela hasta mi sobrina pequeña [...] Esta pieza es acerca de mi conexión a mi madre y a Cuba. El cordón umbilical representa la encrucijada en la cual se encuentra cada madre con su hijo: es a la vez el punto de encuentro y de separación -el sitio que necesitan para que se produzca la separación física [...] Encima está mi abuela -la madre de mi madre- y debajo hay una pequeña placa que dice África. (Bell 36-37) ${ }^{16}$

\section{Puentes y abrazos}

No hay fijeza pero sí trascendencia, escondida entre las trenzas, cordones, dentro de los nidos y madejas de cabellos. A semejanza de "Cordón umbilical", en muchas de sus obras esta trascendencia se instala en una energía matrilineal dominante, y que permite a la artista tender puentes entre sus diferentes realidades e historias, entre África, Cuba y los Estados Unidos. Son travesías, a lo largo de una vasta experiencia de supervivencia racial y genérica, sugerida por ejemplo por los instrumentos de trabajo -reproducciones en vidrio de planchas y tablas de planchar-utilizados en la instalación "Spoken Softly with Mama" (1998).

La elección del vidrio como material en que hace las réplicas de las planchas en esta obra ha sido explicada por la artista, quien alude con ello a cierta

16 "The piece ['Umbilical Cord'] has every single female member of my family from my grandmother to my younger niece at that period. [...] The piece is about my connection to my mother and to Cuba. The umbilical cord is the crossroad at which mother and child meet: it is the point of encounter but it is also the point of separation -the place they need to pull apart physically. $[\ldots]$ At the top is my grandmother -my mother's mother-and at the bottom is this little plaque that says Africa" (Bell 36-37). 
transparencia, que a su vez relaciona con la memoria y el desplazamiento ${ }^{17}$. Vuelve entonces en "Spoken Softly with Mama" el sentido de la inestabilidad identitaria, especialmente en situaciones diaspóricas como las recreadas por Campos-Pons en sus obras. Lo transparente revela pero no se trata tampoco de la copia fiel, total. La identidad es concebida como espejismo.

La artista utiliza con frecuencia en sus instalaciones objetos tradicionalmente empleados por las mujeres en sus quehaceres domésticos, como las planchas ya referidas, o los sillones que aluden a saberes trasmitidos transgeneracionalmente entre mujeres. Los sillones fueron introducidos específicamente en la obra "Meanwhile the girls are playing" (1999-2000), donde Campos-Pons se esfuerza en recrear recuerdos de la presencia de abuela, madre y hermana durante la niñez. Retomando la idea del juego, canturreos, la risa, esta instalación es regida por una ternura ancestral que llega desde su infancia. Parece Campos-Pons reproducir aquí, desde su propia experiencia, las ideas de Audre Lorde cuando afirmaba que: "Como mujeres afroamericanas, conocemos, porque nuestra sangre nos lo dice, la ternura con la que nuestras madres antepasadas se curaban mutuamente las heridas, criaron los hijos de unas y otras"18. Esa ternura maternal ancestral deviene -como la violencia y la rabia-también un pilar identitario para la mujer negra. Se le descubre escondido en ciertos entreactos del performance de la identidad poco visitados tradicionalmente.

Estos objetos propios de la domesticidad cotidiana utilizados por CamposPons, con su carga de tradiciones y sensaciones diversas, ofrecen otras maneras de expresar la Historia, tomando -como ha expresado en entrevistas- los caminos de una frecuentemente intangible comunidad femenina. Así, mientras Fe Verdejo se servía de su cuerpo y el traje de Xica da Silva para hallar otros caminos por los que transita la historia de las mujeres negras en las Américas; la artista cubana utiliza, además de su cuerpo cuya piel negra es ya un poderoso significante, estos objetos propios de la ritualidad familiar, capaces de establecer la continuidad histórica con otro lenguaje. En estas obras se trata, ha expresado Campos-Pons, de crear monumentos, frágiles, con diversas capas o niveles de lectura:

La instalación ["Spoken Softly With Mama"], compuesta de planchas de vidrio, es sobre mi tía y mis primas y sobre la tradición de mujeres planchando para ellas mismas, para los miembros de la familia y para personas extrañas.

17 "Transparency is about memory. Also, I think that transparency [is] about displacement. When you are [an émigré] you are always in this space that is in-between, in-between physical and not seeing, but they are there" (Harris 52).

18 "We are African American women and we know, in our blood's telling, the tenderness with which our foremothers held each other's wounds, raised each other's children [...]" (Lorde, Sister Outsider 152). 
Este tiempo compartido mientras planchan y doblan la ropa se convierte en un escenario para la feminidad, la hermandad entre mujeres, la comunidad. El vidrio representa muchas cosas: fragilidad, transparencia, funcionalidad. Su elegancia sugiere un modo de vida situado al otro extremo de la escala con respecto a las planchadoras. (Bell 35$)^{19}$

La ritualidad, los saberes repetidos transgeneracionalmente, son esenciales en la obra de Campos-Pons. Pero los ritos se componen de diferentes historias que se entrelazan y superponen las unas a las otras. No son, debemos repetir, historias lineales y únicas. Puede enlazarse esta intrincada ritualidad con la utilización que hace Santos Febres de los ritos en Fe en disfraz. La protagonista, como ya he destacado, se vale del rito que anualmente realiza al disfrazarse con el traje de Xica da Silva para reavivar una memoria perdida, el vínculo con sus ancestros, las esclavas africanas cuyo rastro de sangre puede sentir al encajársele en las carnes los hierros del arnés, y que recorre también al estudiar como historiadora sus testimonios. Al respecto, escribe:

Cada rito convoca una fuerza de la cual surgen los nombres y los dioses. [...] Los ancestros son la duplicidad y la contradicción. Los ancestros (y el acopio de sus saberes) son lo que nos fija en el tiempo. Esas largas genealogías de muertos trazan una línea que, atravesando una masa informe de cuerpos, se desplaza por el espacio infinito. (92)

La fusión y el vínculo con su presente aparecen por otra parte expresados en obras como "Sagrada familia" (2000), donde María Magdalena Campos-Pons presenta en una secuencia de fotos, abrazados, los cuerpos de la artista negra, el esposo blanco y el hijo mestizo. Nuevamente se vuelve innecesaria la explicación. Basta el abrazo de los cuerpos para exponer la indefinición identitaria y la imposibilidad de fijar la pertenencia racial. Junto con esta obra, convendría regresar a lo expresado por la artista refiriéndose a "Identity could be a tragedy", su primera pieza analizada en este artículo, pero que funciona perfectamente dentro del contexto de "Sagrada familia":

19 I am creating a monument but it is fragile, it has many layers, many reading levels. [...] The installation [Spoken Softly With Mama] of glass irons is about my aunt and cousins and the tradition of female ironing clothes for themselves, for family members and for strangers. It's a time when they share time together, folding and ironing: it becomes a setting for womanhood, sisterhood, community. The glass stands for many things -fragility, transparency, functionality: its elegance suggests a lifestyle that is at the other end of the scale to the people who iron the clothes" (Bell 35). 
Las identidades pueden resultar dolorosas, restrictivas y peligrosas. Mi idea sobre la búsqueda de la identidad es abrazar al otro [...] En la búsqueda de la identidad necesitamos marcar las diferencias pero lo que queremos encontrar en última instancia son las similitudes -porque en un final hemos nacido, respiramos, amamos, odiamos. (Bell 42) ${ }^{20}$

En el caso de la novela de Mayra Santos Febres, el "abrazo" de los cuerpos propiciaría la interrupción de la fatalidad violenta trasmitida a través de generaciones de mujeres negras violadas. La novela debe culminar con la destrucción del traje que, según le informaran a Fe Verdejo, una vez sobre el cuerpo de las descendientes de Xica da Silva las llevaba a entregarse en desenfreno sexual a los hombres, ejercer la prostitución y aceptar la violación de sus cuerpos. No por azar la monja que la ayudara a encontrar el traje le había recomendado desde el principio que no se lo pusiera. Se suponía que estaba "habitado": "los arneses y la tela han bebido demasiado sudor y demasiadas penas" (Santos 77), explicó entonces la anciana. Quería con sus palabras advertir a Fe de la fuerza de presuntas fatalidades transhistóricas. Es decir, la dolorosa experiencia de generaciones de mujeres negras debía imponerse como fatalidad de una subalternidad que el macabro traje perpetuaba materialmente a través de los siglos.

Pero al final Fe quiere que Martín destroce el traje y, con ello, debería romperse también la cadena de violencias sobre estas mujeres. "Rompe el traje, desgárralo, sácame de aquî" (Santos 115), ordena Fe a Martín, porque comprende que el amasijo de telas con su arnés representan la dominación y las violencias sufridas por ella misma y las mujeres que le precedieron. Desnuda, ya sin el traje que la ata a identidades pasadas -aún presentes en su piel pero no enteramente suyas-, podrá abrazar cabalmente la piel del amante blanco. Tal vez, pudiera sugerir Santos Febres con este final, es necesario ese abrazo para escapar de la cárcel de la historia, de una memoria lacerante. Mas el abrazo constituye además de una ruptura con esa especie de fatalidad histórica, un instante de máximo erotismo en el cual los protagonistas se despojan de sus máscaras y trajes y a través de las heridas que se abren mutuamente en sus cuerpos, alcanzan a compartir su más secreta intimidad el uno con la otra. Esta intimidad compartida es la misma que Audre Lorde exalta en su célebre pieza "Uses of the Erotic: The Erotic as Power", donde reconoce que:

20 "Identities can be painful, restrictive and dangerous. My idea about a search for identity is to embrace the other $[\ldots]$ In the search for identity we need to mark the differences but what we want to find in the end are the similarities -because in the end we are born, we breath, we love, we hate" (Bell 42). 
Compartir la felicidad, sea física, emocional, síquica o intelectual, forma un puente entre quienes la comparten que puede constituir la base para la comprensión de mucho de lo que no es compartido entre éstos, disminuyendo la amenaza que representa sus diferencias". (Lorde, "Uses ..." 56) ${ }^{21}$

Ya vimos en la pieza de Magdalena Campos Pons ese mismo abrazo dentro del cual se trasciende -sin por ello ignorarla- la alteridad, y se acercan los sujetos a la más esencial compenetración humana. Coincide con aquel a través del cual Mayra Santos Febres invoca el abandono en el Otro, expresado por el blanco Martín Tirado, cuyas palabras cierran su novela:

Mi obelisco de carne se hundirá profundo entre las piernas de Fe Verdejo [...] Haré que mi dueña olvide quién ha sido. Historiadora famosa, aprendiz de monja, niña vejada. La haré sudar sin vergüenza hasta que brame sin palabras desde el otro lado de su miedo, desde el otro lado de su soledad. Me hundiré dentro de ella hasta que gritemos juntos. Hasta que olvidemos juntos quienes hemos sido. Abandonarse es, a veces, la única manera de comenzar. (Santos 115)

\section{Obras citadas}

Arce, Chrissy B. "La fe disfrazada y la complicidad del deseo". Lección errante. Mayra Santos Febres y el Caribe contemporáneo. Nadia V. Celis y Juan Pablo Rivera Eds. San Juan: Isla Negra, 2011. 226-246.

Bell, Lynne. "History of People Who Were Not Heroes. A Conversation with María Magdalena Campos-Pons". Third Text 43 (1998).

Butler, Judith. "Imitation and Gender Insubordination". The fudith Butler Reader. Malden (MA), Oxford (UK): Wiley-Blackwell, 2004.

Collins, Patricia H. Black Sexual Politics. Nueva York y Londres: Routledge, 2005.

Freiman, Lisa D. María Magdalena Campos-Pons: Everything is Separated bu Water. New Haven y Londres: Indianpolis Museum of Art en asociación con Yale University Press, 2007.

González Mandri, Flora. Guarding Cultural Memory. Afro-Cuban Women in Literature and the Arts. Charlottesville y Londres: University of Virginia Press, 2006.

21 "The sharing of joy, wether physical, emotional, psychic, or intelectual forms a bridge between the sharers which can be the basis for understanding much of what is not shared between them, and lessens the threat of their difference" (Lorde, "Uses ..." 56). 
Hall, Stuart. "Old and new Identities, Old and new ethnicities".

Theories of Race and Racism: A Reader. Les Back y John Solomos

Eds. Nueva York y Londres: Routledge, 2000. 144-153.

—. "Introducción: ¿Quién necesita la “identidad'?". Cuestiones de Identidad. Stuart

Hall y Paul du Gay Eds. Buenos Aires: Amorrortu Editores, 2003. 13-39.

Harris, Michael D. "Meanwhile the girls were playing: María Magdalena

Campos-Pons". Nka. Fournal of Contemporary African Art (2001). 48-55.

hooks, bell. Yearning. Race, Gender, and Cultural

Politics. Boston: South End Press, 1990.

Lévinas, Emmanuel. Humanisme de l'autre homme. Paris: Biblio, 1987.

Lorde, Audre. Sister Outsider. Essays and Speeches.

Berkeley y Toronto: Crossing Press, 2007.

-. "An Interview: Audre Lorde and Adrienne Rich". Sister Outsider.

Essays and Speeches. Berkeley y Toronto: Crossing Press, 2007.

- "Uses of the erotic: The erotic as power".

Nancy, Jean-Luc. Corpus. Nueva York: Fordham University Press, 2008.

- Identité. Fragments, franchises. París: Galilée, 2010.

Santos Febres Mayra. Fe en disfraz. Doral (FL): Alfaguara, 2009.

—. Sobre piel y papel. San Juan (PR): Ediciones Callejón, 2005. 